\title{
Fabrication and characterization of a magnetized metal- encapsulated FBG sensor for structural health monitoring
}

\author{
Sagar Jinachandran \\ University of Wollongong \\ Huijun Li \\ University of Wollongong \\ Jiangtao Xi \\ University of Wollongong
}

See next page for additional authors

Follow this and additional works at: https://arrow.tudublin.ie/prcart

Part of the Electrical and Computer Engineering Commons

\section{Recommended Citation}

S. Jinachandran et al., "Fabrication and Characterization of a Magnetized Metal-Encapsulated FBG Sensor for Structural Health Monitoring," in IEEE Sensors Journal, vol. 18, no. 21, pp. 8739-8746, 1 Nov.1, 2018, doi: 10.1109/JSEN.2018.2866803.

This Article is brought to you for free and open access by the Photonics Research Centre at ARROW@TU Dublin. It has been accepted for inclusion in Articles by an authorized administrator of ARROW@TU Dublin. For more information, please contact arrow.admin@tudublin.ie, aisling.coyne@tudublin.ie,gerard.connolly@tudublin.ie.

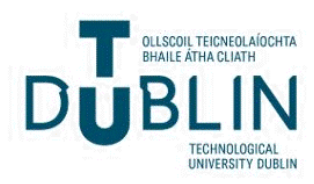




\section{Authors}

Sagar Jinachandran, Huijun Li, Jiangtao Xi, B. Gangadhara Prusty, Yuliya Semenova, Gerald Farrell, and Ginu Rajan

This article is available at ARROW@TU Dublin: https://arrow.tudublin.ie/prcart/25 


\title{
Fabrication and Characterization of a Magnetized Metal-Encapsulated FBG Sensor for Structural Health Monitoring
}

\author{
Sagar Jinachandran, Huijun Li, Jiangtao Xi, B. Gangadhara Prusty, \\ Yuliya Semenova $^{\circledR}$, Gerald Farrell, and Ginu Rajan
}

\begin{abstract}
A novel means of metal packaging of a fiber Bragg grating (FBG) sensor using stainless steel and tin, together with high temperature resistant samarium cobalt (SmCo) magnet is proposed in this paper. The inclusion of high temperaturecapable SmCo magnets enable the metal packaging of the FBG sensor with magnetic capabilities. This packaged sensor can be placed in direct contact with the substrate structures such as iron pipelines and other ferromagnetic components without any adhesives, making them easily detachable and reusable. This is a significant improvement compared with other commercial fiber optic sensors which are, surface attached using epoxies or welded to the substrate. The design parameters and characteristic properties such as load, temperature, and vibration sensitivity of the magnetic metal-packaged FBG sensor are studied numerically and validated experimentally to demonstrate the feasibility of using the encapsulated reusable FBGs for structural health monitoring of compatible structures.
\end{abstract}

Index Terms-Acoustic emission sensors, fiber Bragg gratings, strain, temperature, welding.

\section{INTRODUCTION}

$\mathbf{S}$ TRUCTURAL health monitoring (SHM) using optical fibre sensors (OFS) is a fast developing area of research and the design and development of field-usable sensors is currently accelerating [1]. Continuous assessment of the integrity of structures such as those used in pipelines, automotive, military applications, nuclear energy, and bridges is essential for preventative maintenance and to predict possible operational failure. This requires implementation of adequate methods for SHM of metal structures [2], [3]. In order to detect damage and failures, various types of sensors that measure parameters such as vibration, temperature, strain

Manuscript received May 28, 2018; revised August 13, 2018; accepted August 13, 2018. Date of publication August 23, 2018; date of current version October 10, 2018. The associate editor coordinating the review of this paper and approving it for publication was Dr. Carlos Marques. (Corresponding author: Sagar Jinachandran.)

S. Jinachandran, J. Xi, and G. Rajan are with the School of Electronics, Computer and Telecommunication Engineering, University of Wollongong, Wollongong, NSW 2522, Australia (e-mail: sj317@uowmail.edu.au; ginu@uow.edu.au).

H. Li is with the School of Mechanical, Materials, Mechatronics and Biomedical Engineering, University of Wollongong, Wollongong, NSW 2522, Australia.

B. G. Prusty is with the School of Mechanical and Manufacturing Engineering, University of New South Wales, Kensington, NSW 2052, Australia.

Y. Semenova and G. Farrell are with the Photonics Research Centre, Dublin Institute of Technology, Dublin 8, D08 X622 Ireland.

Digital Object Identifier 10.1109/JSEN.2018.2866803 and stress are integrated with the structures. Among a number of currently available sensors, OFSs are becoming popular due to their capability to be embedded in, or attached to, a structure without affecting its operation [1]. Compared with conventional electric and mechanical sensors, OFSs have unique properties such as light weight, compact size, long-term durability, good linearity, immunity to external electromagnetic interference and resistance to corrosion [4], [5].

Among the different types of fibre sensors, fibre Bragg gratings (FBGs) are widely used and are one of the most popular technology for SHM systems [6]-[8]. The unique capabilities of FBGs to measure multiple parameters make them attractive and also commercially viable. However, along with these advantages, they have limitations such as a degraded performance at elevated temperatures, lack of suitable packaging for direct field deployment and cross-sensitivity between strain and temperature [9].

Several methods have been proposed to package FBGs in metal [10]-[13] for field deployment applications. Li et al. [10] illustrated embedding of FBGs by layered manufacturing using nickel and stainless steel which was then characterised for strain and temperature measurements and found that this method of embedding will increase the temperature sensitivity of FBGs. Alemohammad and Toyserkan [11] demonstrated a way of packaging FBGs in which a thin film of silver is deposited on the fibre using a low-temperature laser microdeposition method followed by nickel electroplating on steel using microscale laser-based direct writing method before embedding. This method can be utilised for temperatures of about $200{ }^{\circ} \mathrm{C}$. Some of the other methods reported are aluminium and nickel electroplating, brazing, and ultrasonic welding with aluminium and tin substrates [11]-[13]. The strain sensitivity of FBGs can also be enhanced by using ceramic coatings such as an aluminium oxide coating spray which can be used in high -temperature applications requiring operation up to $600{ }^{\circ} \mathrm{C}[14]-[16]$.

In this paper, we propose, and demonstrate a novel method for metal packaging of FBG sensors, using stainless steel and tin, together with samarium cobalt ( $\mathrm{SmCo}$ ) magnets, so that they can be easily attached to structures such as iron pipelines and can operate at high temperatures. The proposed configuration will provide a metal-packaged FBG sensor which can be directly used in a range of applications, 
without any installation complications, in contrast to other similar commercial sensors which are surface attached using epoxies or welded to the substrate structure.

Section 2 of the paper describes the design and fabrication methods for the packaged FBGs. Analysis of the design is conducted using ANSYS workbench and is presented in Section 3. The experimental arrangements for the characterization of the fabricated sensors are discussed in section 4 and results are discussed in Section 5. It is expected that the outcome of this study will pave a way for a new economical surface mountable packaging technology for FBGs that can operate at high temperatures.

\section{Design and Fabrication of the Magnetic and Metallic Packaged FBGs}

An FBG comprises a short section of single-mode optical fibre in which the core refractive index is periodically spatially modulated using an intense optical interference pattern, typically at UV wavelengths [5]-[6]. The light reflected by the periodic variation of the refractive index of the Bragg grating has a central wavelength $\lambda_{B}$ given by;

$$
\lambda_{B}=2 n_{e f f} \Lambda,
$$

where $\Lambda$ is the grating period and $n_{\text {eff }}$ is effective refractive index of the fibre. The operation of an FBG strain or temperature sensor is based on the measurement of the peak wavelength shift induced by applied strain or a change in temperature [17]. The temperature sensitivity of the FBG arises from the change in its period associated with the thermal expansion of the fibre, coupled with a change in the refractive index arising from the thermo-optic effect. The strain sensitivity arises from the change in the period of the fibre grating due to applied strain coupled with a change in the refractive index arising from the strain-optic effect. The temperature-induced wavelength shift for the peak reflected signal from a FBG is given by;

$$
\Delta \lambda_{B}=\lambda_{B} \Delta T(\alpha+\xi),
$$

where $\alpha$ is the thermal expansion coefficient, and $\xi$ is the thermo-optic coefficient of fibre material [17]. Similarly the strain induced wavelength shift can be expressed as;

$$
\Delta \lambda_{B}=\lambda_{B}\left(1-p_{\alpha}\right) \Delta \varepsilon
$$

where $\Delta \varepsilon$ is the induced static strain, and $p_{\alpha}$ is the photoelastic coefficient. For silica fibre the value of $\left(1-p_{\alpha}\right)$ is usually 0.78 . Thus by measuring the wavelength shift, changes in temperature or strain can be determined [18]. Similarly for vibration induced dynamic strain, the corresponding dynamic wavelength shift can be written as

$$
\Delta \lambda_{B}(z, t)=\lambda_{B}\left(1-p_{\alpha}\right) \Delta \varepsilon(z, t) .
$$

Where $z$ is the axial direction along which longitudinal strain propagates and $t$ is the time.

It should be also noted that a typical FBG starts to deteriorate at high temperatures close to $400{ }^{\circ} \mathrm{C}$ and with a further increase in temperature the degradation is rapid [19], [20] and structural deterioration can occur [21], [22]. The FBGs used in this work were obtained from DK photonics and were $10 \mathrm{~mm}$ long with polyimide buffer coating and with peak reflected wavelengths of circa 1540 and $1550 \mathrm{~nm}$, side lobe suppression ratio (SLSR) higher than $15 \mathrm{~dB}$, peak reflectivity greater than $90 \%$ and a bandwidth of $<0.3 \mathrm{~nm}$. The maximum operating temperature of the polyimide-coated FBG sensors used in this experiment is $300{ }^{\circ} \mathrm{C}[23]$.

\section{A. Design, Fabrication of the Packaged Sensor}

A cylindrical stainless-steel container is machined as shown in Fig 1(a). A disc, was machined from tin to be inserted into the cylinder (Fig 1(b)). A $1 \mathrm{~mm}$-diameter hole was drilled into the centre of the container base as well as the tin disc for insertion of the optical fibres. Prior to assembly of the sensor, the FBGs were sheathed in a $30 \mathrm{~mm}$-long and $1 \mathrm{~mm}$-outside diameter teflon tube for protection and to impart strength to the optical fibre where it entered and exited the assembly. Four cylindrical SmCo magnets were positioned inside the container as shown in Fig. 1(c). SmCo was chosen as the magnetic material to be incorporated in this design, given its ability to withstand high temperatures and also allowed a means to position a fibre in the centre of a stainless steel container. Typically permanent magnets lose their magnetic capabilities at higher temperatures. For commonly used neodymium magnets, the operating temperature is up to $150{ }^{\circ} \mathrm{C}$. Recently SmCo based permanent magnets have attracted interest due to their superior high-temperature properties [24], [25]. In SmCo, the interatomic exchange between the cobalt atoms gives rise to higher Curie temperatures, which depend on the transition metal sub lattice. Therefore, SmCo can have a Curie temperature of about $800{ }^{\circ} \mathrm{C}$ and an operating temperature of around $350{ }^{\circ} \mathrm{C}$. It was for this reason that SmCo was chosen as the magnet to be incorporated in this design. Solid cylindrical magnets of $6.25 \mathrm{~mm}$ diameter and $12.7 \mathrm{~mm}$ height were used allowing for the FBG to be inserted between the magnets and accommodated easily as shown in Fig 1(c). For each sample the sheathed FBG was inserted through the hole in the tin disc (as shown in Fig 1(b)) and then into the central hole between the magnets. The entire assembly was then heated in an oven to $270{ }^{\circ} \mathrm{C}$, which is significantly higher than the melting point of tin $\left(232{ }^{\circ} \mathrm{C}\right)$ so that the tin disc melts and entirely fills the container. The sensor assembly was then allowed to cool to room temperature. The assembly process and the fabricated metal packaged sensor are shown in Fig. 1(d) and 1(e) respectively. Tin was used for the binding material as it does not react with stainless-steel. The properties of materials such as the Young's modulus, Poisson ratio and the density of the material used in the design are shown in table I.

The reflection spectra of the FBG were monitored before and after packaging using a commercial FBG interrogator (I-MON 256, Ibsen Photonics). A schematic diagram of the FBG interrogation setup used in this study is shown in Fig. 2. The interrogator has a wavelength resolution of $5 \mathrm{pm}$ with a maximum data acquisition rate of $6 \mathrm{kHz}$, and is connected to a broadband source with a spectral range of $1530-1580 \mathrm{~nm}$. The reflected signal from the FBG was directed to the interrogator 


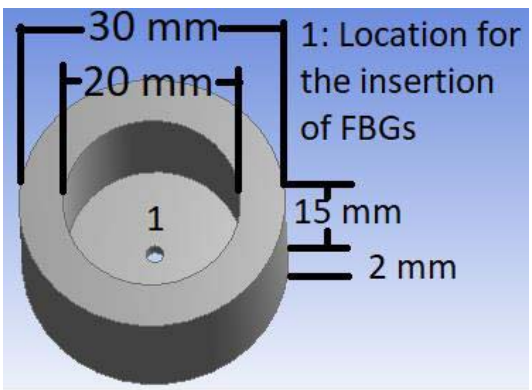

(a)

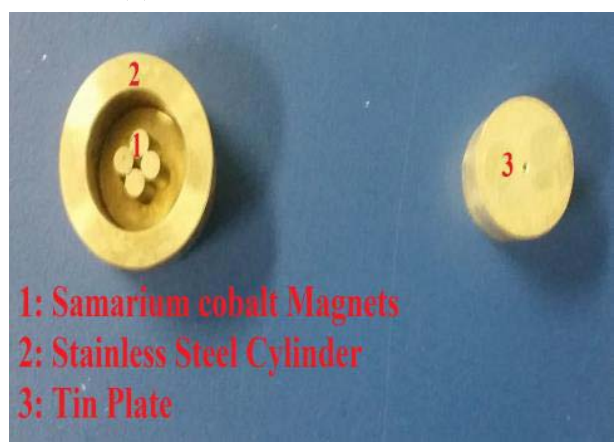

(d)

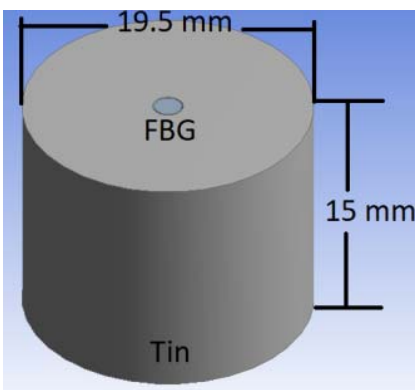

(b)

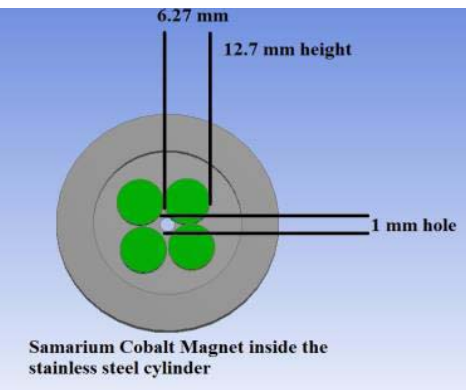

(c)

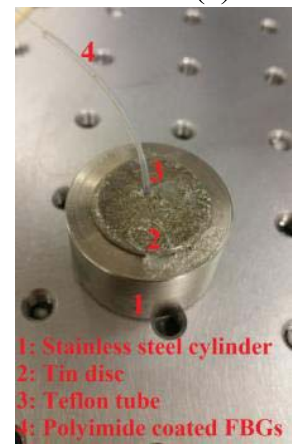

(e)

Fig. 1. The schematic of (a) stainless steel cylinder region (b) cross section view of the tin disc (c) placement of SmCo magnets within the cylinder (d) the fabrication of the metal packaged magnetic FBG sensors components before the embedding, indicating the location of the SmCo magnets, stainless steel cylinder and tin discs (e) the metallic packaged FBG sensor.

TABLE I

The Material Data For Simulation In ANSYS

\begin{tabular}{|c|c|c|c|c|}
\hline Material & $\begin{array}{c}\text { Youngs } \\
\text { Modulus } \\
(\mathrm{Pa})\end{array}$ & $\begin{array}{c}\text { Poisson's } \\
\text { ratio }\end{array}$ & $\begin{array}{c}\text { Thermal } \\
\text { Expansion } \\
\text { coefficient } \\
\left(\mathrm{K}^{-1}\right)\end{array}$ & $\begin{array}{c}\text { Density } \\
\left(\mathrm{kg} \mathrm{m}^{-}{ }^{3}\right)\end{array}$ \\
\hline $\begin{array}{c}\text { Stainless } \\
\text { steel }\end{array}$ & $1.93 \times 10^{11}$ & 0.31 & $1.7 \times 10^{-5}$ & 7750 \\
\hline Tin & $5 \times 10^{10}$ & 0.25 & 22 & 7304 \\
\hline $\begin{array}{c}\text { Samarium } \\
\text { Cobalt }\end{array}$ & $1.2 \times 10^{11}$ & 0.27 & $13 \times 10^{-6}$ & 0.008 \\
\hline $\begin{array}{c}\text { Optical } \\
\text { fibre }\end{array}$ & $2.5 \times 10^{9}$ & 0.34 & 50 & 1400 \\
\hline
\end{tabular}

through a fibre circulator. The reflection spectra of the FBG before and after packaging are shown in Fig. 3. Though the reflectivity signal is reduced, no peak distortion was observed due to the packaging. It is observed that the peak reflected wavelength of the FBG before embedding was $1549.82 \mathrm{~nm}$ and the wavelength after embedding is $1549.76 \mathrm{~nm}$. As the FBG was heated for only three hours at high temperature during the fabrication, the thermal decay to optical fibre material is not considered to be significant. However the observed blue shift of $48 \mathrm{pm}$ to the FBG signal after fabrication indicates a residual strain developed within the material after the packaging which is a common phenomenon.

\section{B. Analysis of the Design Using the Finite Element Method (FEM)}

The packaged FBG is subjected to strain during fabrication due to the thermal expansion of the encapsulating material.

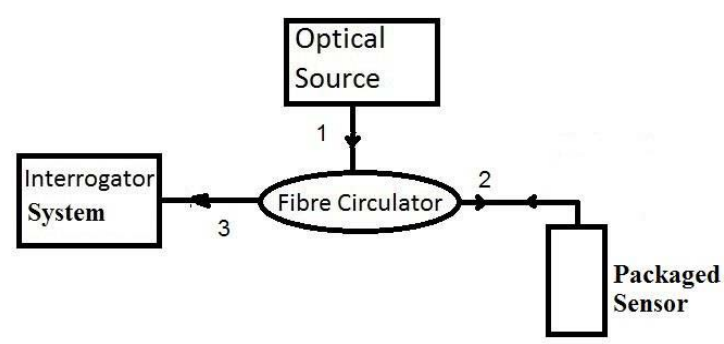

Fig. 2. The schematic diagram of the FBG interrogation system.

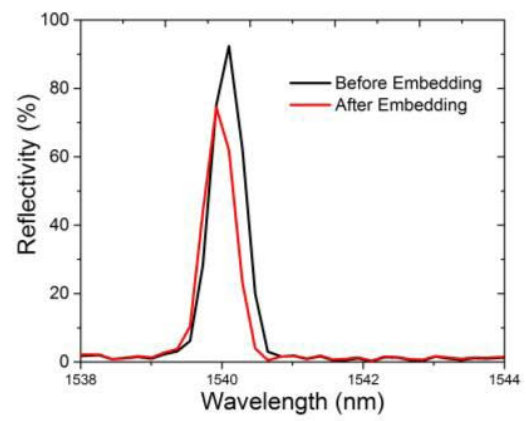

Fig. 3. Reflection spectra of the FBG sensor before and after the packaging.

An ANSYS-based simulation tool was used to study the impact of stress and strain caused by heating on the embedded FBG sensor. We performed FEM simulation of the proposed design with the dimensions and materials as discussed in section IIA.

For the FEM analysis, the size of the meshing is selected as auto and a triangular mesh is generated which encloses 


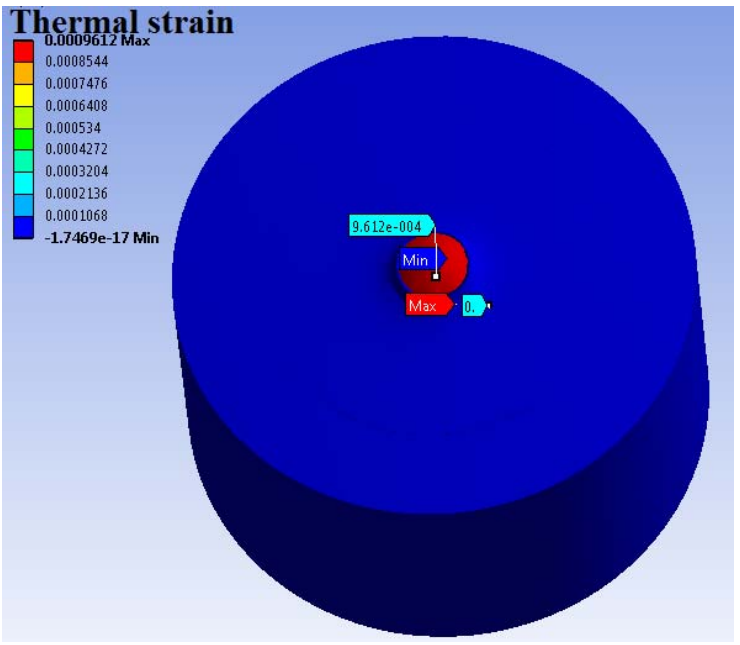

(a)

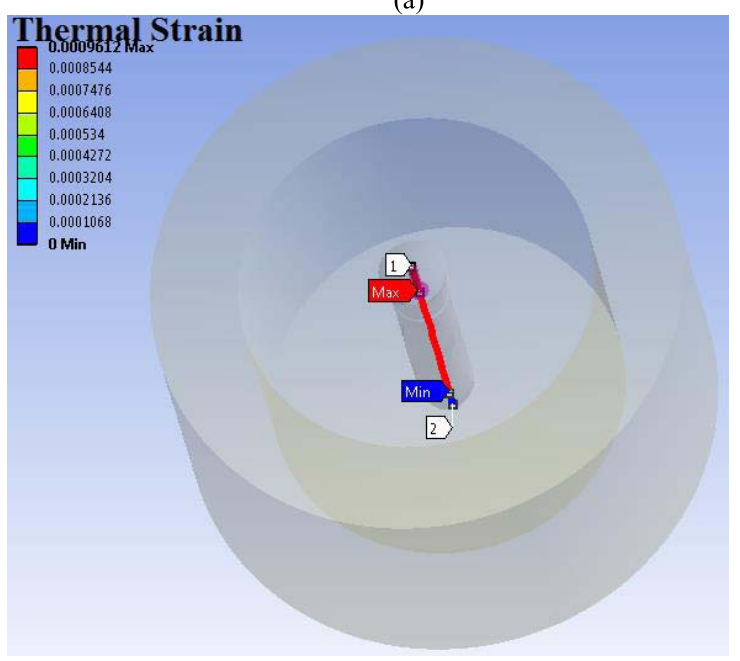

(b)

Fig. 4. (a) Thermal strain profile of the packaged sensor due to applied temperature (b) the thermal strain along the embedded fibre containing the FBG.

the structure and the material properties such as the Young's modulus, Poisson ratio and the density of the material used in the design are shown in Table 1. The temperature was applied using the transient structural tool box to act on the whole of the structure. In both the cases a path was defined along the length of the FBG and the resultant strains for both the temperature and load were calculated. The numerical model was analysed to calculate the induced thermal strain as the temperature is increased from $20{ }^{\circ} \mathrm{C}$ to $200{ }^{\circ} \mathrm{C}$ during fabrication. Fig 4(a) shows the overall thermal strain in the structure, while Fig 4(b) shows the thermal strain experienced by the fibre containing the FBG. From Fig 4(b) the thermal strain induced on the fibre is calculated as $961.2 \mu \varepsilon$ over a temperature change of 20 to $200{ }^{\circ} \mathrm{C}$ which gives a thermal strain sensitivity of $0.4806 \mu \varepsilon /{ }^{\circ} \mathrm{C}$ for the $\mathrm{FBG}$ which equates to a change of $4.005 \mathrm{pm} /{ }^{\circ} \mathrm{C}$. The standard temperature sensitivity for a polyimide coated $\mathrm{FBG}$ is $10 \mathrm{pm} /{ }^{\circ} \mathrm{C}$ and the total thermal sensitivity of an FBG is the sum of the free space temperature sensitivity and thermal strain sensitivity and is estimated as $14.005 \mathrm{pm} /{ }^{\circ} \mathrm{C}$.
To estimate the load sensitivity of the packaged FBG sensor we numerically calculated load-induced strain. The loads were simulated to be acting on the tin region of the packaged sensor, and a fixed support was also placed at the base of the structure. The load range was selected from $0 \mathrm{~N}$ to $25 \mathrm{~N}$ in $5 \mathrm{~N}$ increments, applied on the base of the structure, and it was solved for the equivalent elastic strain on the FBG. The obtained elastic strain shows the expected strain values for the loads applied and it is calculated that for $25 \mathrm{~N}$ of applied load the embedded FBG experiences a strain of $19.46 \mu \varepsilon$ which equates to a strain sensitivity of $0.7784 \mu \varepsilon / \mathrm{N}$. The strain distribution in the FBG and in the packaged material with applied load is shown in Fig 5(a) whereas the strain distribution along the FBG is shown in Fig 5(b), and a linear change in strain is experienced by the FBG with applied load when the simulation is carried out, this linear change is shown in Fig 5(c).

\section{EXPERIMENTAL SETUP FOR CHARACTERIZATION of The Metal PaCKaged FBGs}

The packaged FBG sensors were characterised for load, temperature and vibration. The experimental arrangements for characterization are shown in Fig 6 (a)-(c).For load characterization, force was manually applied to the packaged sensor using a mechanical bench vise longitudinally along the sensor as shown in Fig 6(a). The applied forces are then measured using a button load cell SLB-100 which is placed between the packaged sensor and the load application point, with a measurement range of $440 \mathrm{~N}$. The theoretical percentage of error of the load cell used was $\pm 0.25 \%$ RO (SLB100). The loads of up to $25 \mathrm{~N}$ are applied with an increment of $5 \mathrm{~N}$ and the corresponding wavelength shift is measured. The applied load for each increment was measured using the load cell connected to a load cell conditioner unit SCC-SG24 and a data acquisition board (NI6321e) and controlled via a LabView program. For temperature characterization, the packaged sensor is placed in a carbolite laboratory chamber furnace, and the temperature is increased up to $200{ }^{\circ} \mathrm{C}$ in increments of $5{ }^{\circ} \mathrm{C}$. As the melting point of tin is $232{ }^{\circ} \mathrm{C}$, the packaged sensor was characterised only up to $200{ }^{\circ} \mathrm{C}$. After the set up reaches the desired temperature it is kept at that temperature for approximately 10 minutes. This time was allowed between each temperature recording to make sure that the temperature uniformity throughout the packaged sensor structure was achieved. The temperature attained by the packaged sensor was then verified using an infrared temperature sensor. The shift in the peak reflected wavelength induced by the temperature change was recorded by the interrogator. To evaluate the vibration measurement capability of the packaged sensor mechanical excitations were applied to the sensor using tuning forks of frequency $500 \mathrm{~Hz}$ and $1 \mathrm{kHz}$. The packaged $\mathrm{FBG}$ sensor was placed on the mechanical bench vise so that there is a firm support for the packaged FBG sensor and then the tin region of the packaged FBG sensors are excited using the tuning forks as shown in Fig 6(c). The vibrationinduced dynamic wavelength shift was then measured using an interrogator capable of measuring at frequencies of up to $3 \mathrm{kHz}$. Fast Fourier transform (FFT) of the experimental 


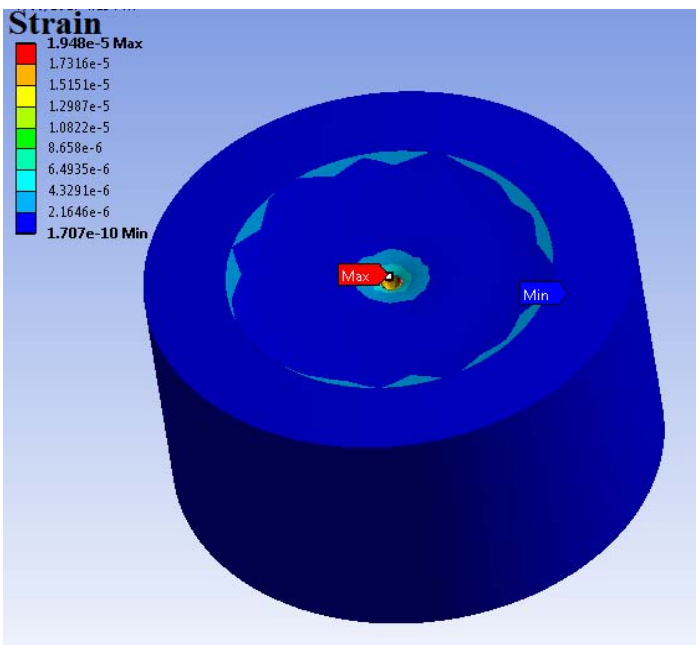

(a)

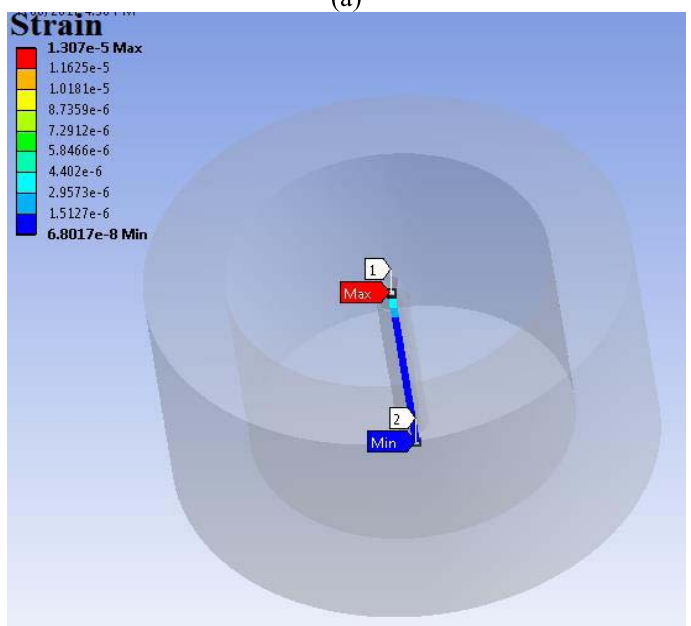

(b)

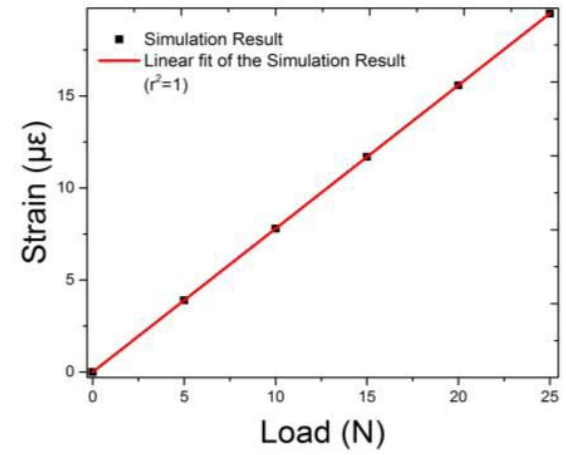

(c)

Fig. 5. (a) Strain profile of the packaged sensor with applied load (b) strain experienced by the embedded optical fibre (c) simulated load vs. strain plot of the packaged sensor.

data was also calculated and The sampling frequency for FFT is same as the sampling rate used which was $2400 \mathrm{~Hz}$ and the frequency resolution was 0.01667 . No windowing, averaging or overlapping was used, to verify the applied and measured frequencies [26].

\section{Results AND Discussions}

The load-induced wavelength shift of the FBG corresponding to the applied load is shown in Fig 7. Here two sets of data



(a)

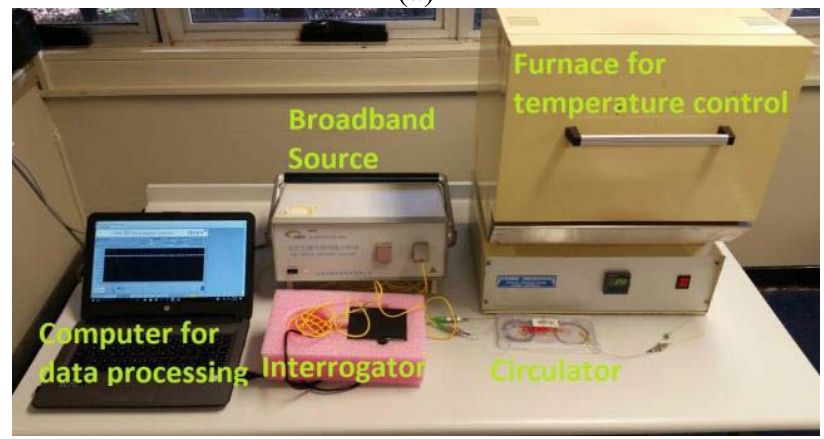

(b)

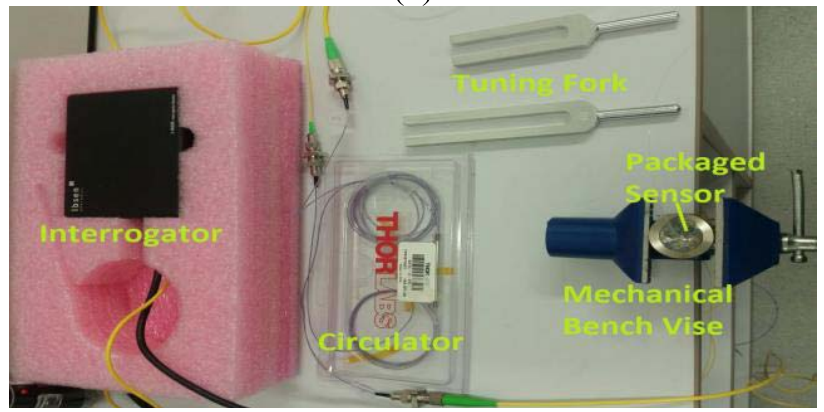

(c)

Fig. 6. The photographs of the set up for characterisation (a) load (b) temperature (c) vibration.

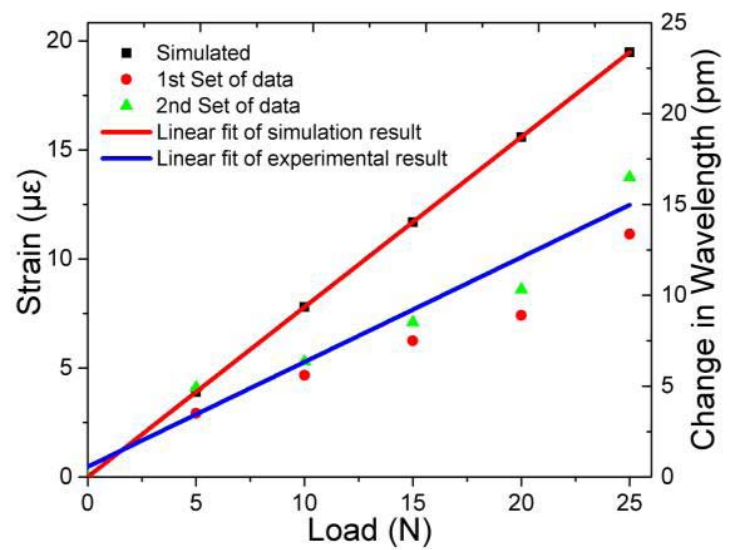

Fig. 7. Measured wavelength shift and calculated strain due to applied load calculated strain from the experiment due to applied load and its comparison with the simulation.

were obtained in order to obtain the error bars for the data after comparing the two sets of data, and the corresponding strain is calculated and is shown in Fig. 7. A linear fit to 


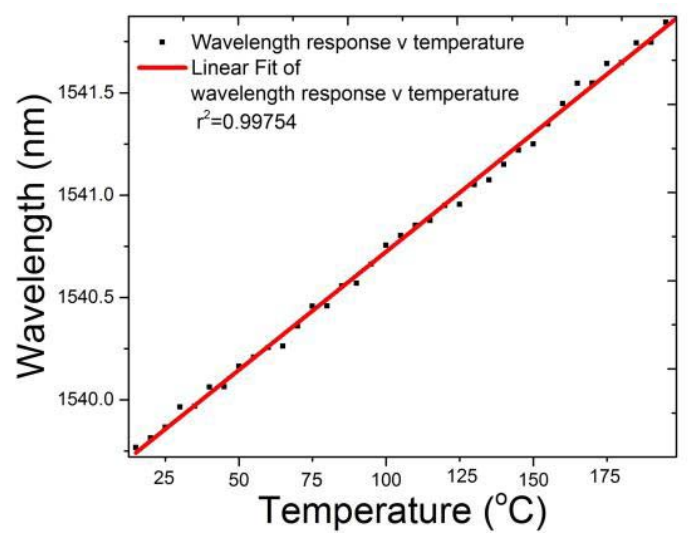

Fig. 8. Measured temperature induced wavelength shift of the packaged sensor.

the measured data is shown in the figures. A strain value of $13.37 \mu \varepsilon$ is obtained for an applied load of $25 \mathrm{~N}$. This corresponds to a sensitivity of $0.5348 \mu \varepsilon / \mathrm{N}$ or $0.4456 \mathrm{pm} / \mathrm{N}$. The trend agrees well with the simulation results which calculated a sensitivity of $0.7784 \mu \varepsilon / \mathrm{N}$ and are also shown in Fig 7 the difference in between the simulation and the experiment may be because of the different loading and boundary conditions. The load sensitivity of the FBGs reported in the literature is in the range of approximately $0.1285 \mathrm{pm} / \mathrm{N}-1.933 \mathrm{pm} / \mathrm{N}$ [27], [28]. Compared to these values, the sensitivity of the proposed packaged sensor is in the lower mid-range of the reported ones, however it can be enhanced by re-scaling the design and packaging dimensions.

The Bragg wavelength shift of the packaged sensor with temperature was measured and is shown in Fig 8. The temperature sensitivity of the metal-packaged FBG derived from the results is $11.16 \mathrm{pm} /{ }^{\circ} \mathrm{C}$. This shows that the temperature sensitivity of the packaged FBG sensors is less than the simulated result of $14.00 \mathrm{pm} /{ }^{\circ} \mathrm{C}$. The difference between the results may be due to the difference in the applied heating and boundary conditions.

The vibration charactersitics of the packaged sensor were measured. Fig. 9(a) shows the dynamic wavelength change of the sensor the sudden change in the wavelength at 5.5 seconds corresponds to the time when it is excited using a $500 \mathrm{~Hz}$ tuning fork and the corresponding FFT, is shown in Fig. 9(b). From the figures it is clear that the excitation event is resolvable with the FFT showing a measured peak at $502 \mathrm{~Hz}$ and its corresponding first harmonic. The measured frequency for a $1000 \mathrm{~Hz}$ excitation was $931 \mathrm{~Hz}$.

This confirms that the fabricated metal-packaged sensor can detect vibrations and upon using with a suitable interrogation system, high frequency vibrations can be measured. Thus the feasibility of the packaged sensor to pick up the vibrations were successfully demonstrated. It is expected that the metal embedded sensors can have a wide range of applications and can be used in many industries such as manufacturing, the aerospace industry, the oil industry, the power industry, the automotive industry and the construction sector [20]. As such the proposed and demonstrated design of the metalpackaged sensor with magnetic capabilities can simplify field deployments for FBG sensors in the above application areas.

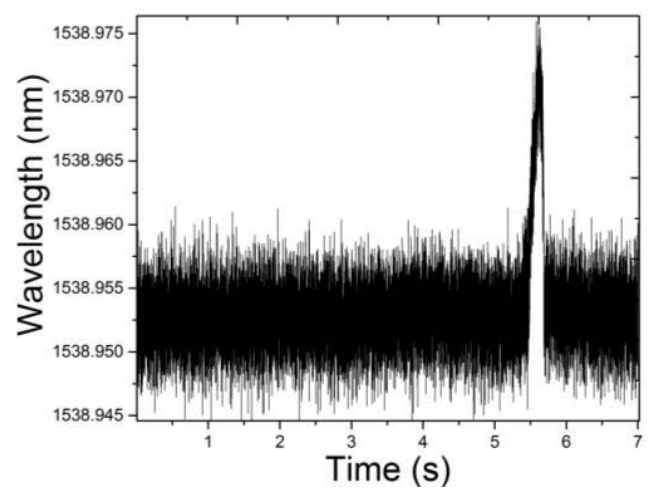

(a)

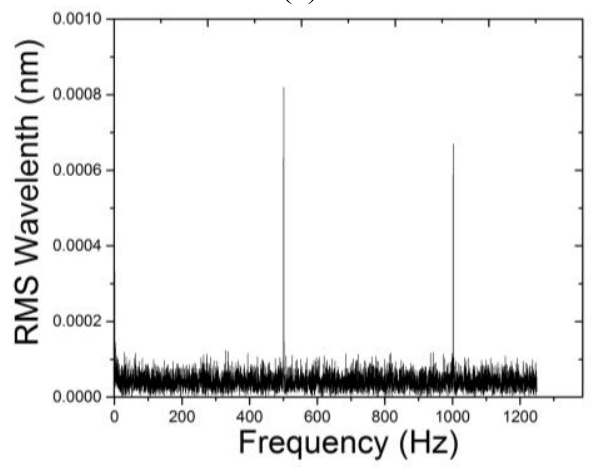

(b)

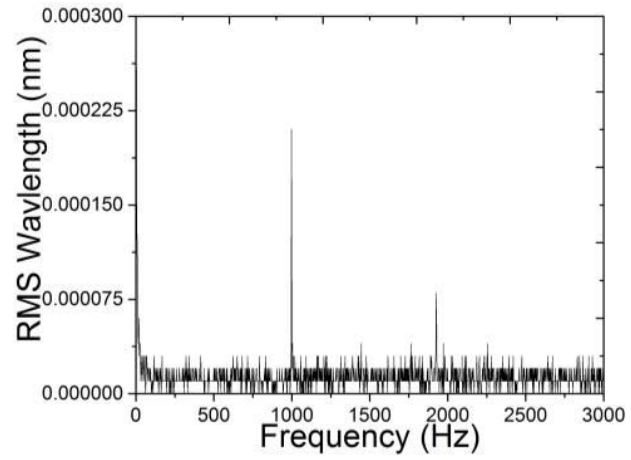

(c)

Fig. 9. (a) the wavelength v. time plot of the vibration experiment (b) the FFT plot for the measured vibration at $500 \mathrm{~Hz}$, (c) the FFT plot for the measured vibration at $1 \mathrm{kHz}$

\section{CONClusion}

A novel means to fabricate a metal-packaged magnetic, reusable FBG was demonstrated in this paper using stainless steel and tin together with SmCo magnets. The design of the structure was analysed by finite element analysis using ANSYS. The simulation results show a temperature sensitivity $14.005 \mathrm{pm} /{ }^{\circ} \mathrm{C}$ and a load sensitivity of $0.7784 \mu \varepsilon / \mathrm{N}$. The stand-alone packaged sensor has been characterised for load, temperature, and vibration and were compared with the simulation results. The measured load and temperature sensitivity of the packaged sensor were $0.4456 \mu \varepsilon / \mathrm{N}$ and $11.16 \mathrm{pm} /{ }^{\circ} \mathrm{C}$ respectively. The behaviour of the simulated and experimental packaged sensor were similar but the small difference in the sensitivity values are attributed to the different boundary conditions in the experiment and simulation. The vibration measurement capability of the packaged sensor 
was also demonstrated by exciting the packaged sensor at two different frequencies and the measured frequency was in close agreement with the applied frequency. The ease of fabrication, low cost, detachability and reusability of the metalencapsulated FBG can make it an excellent choice for SHM especially for ferrous pipeline monitoring and for welded structures.

\section{REFERENCES}

[1] G. Rajan and B. G. Prusty, Structural Health Monitoring of Composite Structures Using Fiber Optic Methods. Boca Raton, FL, USA: CRC Press, 2016.

[2] H.-N. Li, D.-S. Li, and G.-B. Song, "Recent applications of fiber optic sensors to health monitoring in civil engineering," Eng. Struct., vol. 26, no. 11, pp. 1647-1657, 2004.

[3] S. Minakuchi and N. Takeda, "Recent advancement in optical fiber sensing for aerospace composite structures," Photon. Sensors, vol. 3, no. 4, pp. 345-354, 2013.

[4] G. Pereira, C. Frias, H. Faria, O. Frazão, and A. T. Marques, "Study of strain-transfer of FBG sensors embedded in unidirectional composites," Polymer Test., vol. 32, no. 2, pp. 1006-1010, 2013.

[5] R. Kashyap, Fiber Bragg Gratings, 2nd ed. Burlington, MA, USA: Academic, 2010.

[6] A. Othonos and K. Kalli, Fiber Bragg Gratings: Fundamentals and Applications in Telecommunications and Sensing. Norwood, MA, USA: Artech House, 1999, pp. 301-389.

[7] Q. Ye, Q.-B. Wang, H.-T. Zhao, J.-A. Chen, and Y.-Y. Wang, "Review on composite structural health monitoring based on fiber Bragg grating sensing principle," J. Shanghai Jiatong Univ., Sci., vol. 18, no. 2, pp. 129-139, 2013.

[8] B. A. Tahir, J. Ali, and R. A. Rahman, "Strain measurements using fibre Bragg grating sensor," Amer. J. Appl. Sci., special issue, pp. 40-48, 2005.

[9] K. O. Hill and G. Meltz, "Fiber Bragg grating technology fundamentals and overview," J. Lightw. Technol., vol. 15, no. 8, pp. 1263-1276, 1997.

[10] X. C. Li, F. Prinz, and J. Seim, "Thermal behavior of a metal embedded fiber Bragg grating sensor," Smart Mater. Struct., vol. 10, no. 4, pp. $575-579,2001$.

[11] H. Alemohammad and E. Toyserkani, "Metal embedded optical fiber sensors: Laser-based layered manufacturing procedures," J. Mater. Sci. Eng., vol. 133, no. 3, p. 031015, 2011.

[12] R. P. Beukema, "Embedding technologies of FBG sensors in composites: Technologies, applications and practical use," in Proc. 6th Eur. Workshop Structural Health Monit., 2012, pp. 1-8.

[13] X. Li, F. Prinz, and R. H. Adams, "Metal embedded fiber Bragg grating sensors in layered manufacturing," J. Manuf. Sci. Eng., vol. 125, no. 3, pp. 577-585 , Jul. 2003.

[14] S. Sandlin, T. Kinnunen, J. Rämö, and M. Sillanpää, "A simple method for metal re-coating of optical fibre Bragg gratings," Surf. Coatings Technol., vol. 201, no. 6, pp. 3061-3065, 2006.

[15] C. Y. Kong and R. Soar, "Method for embedding optical fibers in an aluminum matrix by ultrasonic consolidation," Appl. Opt., vol. 44 no. 30 , pp. $6325-6333,2005$.

[16] C. Lupi et al., "Metal coating for enhancing the sensitivity of fibre Bragg grating sensors at cryogenic temperature," Smart Mater. Struct., vol. 14, no. 6, pp. N71-N76, 2005

[17] Y. J. Rao, "In-fibre Bragg grating sensors," Meas. Sci. Technol., vol. 8, no. 4, pp. 355-375, 1997

[18] G. Rajan, Y. Semenova, and G. Farrell, "Analysis and performance evaluation of an all-fiber wide range interrogation system for a Bragg grating sensor array," J. Opt. A, Pure Appl. Opt., vol. 11, no. 5, p. 054004, 2009.

[19] V. Mishra, M. Lohar, and A. Amphawan, "Improvement in temperature sensitivity of FBG by coating of different materials," Optik-Int. J. Light Electron Opt., vol. 127, no. 2, pp. 825-828, 2016.

[20] W. Morey, G. Meltz, and J. M. Weiss, "Recent advances in fiber grating sensors for utility industry applications," Proc. SPIE, vol. 2594, pp. 9098, Jan. 1995

[21] B. Zhang and M. Kahrizi, "High-temperature resistance fiber Bragg Grating temperature sensor fabrication," IEEE Sensors J., vol. 7, no. 4, pp. 586-591, Apr. 2007.

[22] Y. Shen et al., "Thermal decay characteristics of strong fiber Bragg gratings showing high-temperature sustainability," J. Opt. Soc. Amer. B, Opt. Phys., vol. 24, no. 3, pp. 430-438, 2007.
[23] P. Lu, L. Men, and Q. Chen, "Polymer-coated fiber Bragg grating sensors for simultaneous monitoring of soluble analytes and temperature," IEEE Sensors J., vol. 9, no. 4, pp. 340-345, Apr. 2009.

[24] J. Zhou, R. Skomski, C. Chen, G. C. Hadjipanayis, and D. J. Sellmyer, "Sm-Co-Cu-Ti high-temperature permanent magnets," Appl. Phys. Lett., vol. 77, no. 10, pp. 1514-1516, 2000.

[25] R. Skomski, "Finite-temperature behavior of anisotropic two-sublattice magnets," J. Appl. Phys., vol. 83, no. 11, pp. 6724-6726, 1998.

[26] G. Rajan et al., "Analysis of vibration measurements in a composite material using an embedded PM-PCF polarimetric sensor and an FBC sensor," IEEE Sensors J., vol. 12, no. 5, pp. 1365-1371, May 2012.

[27] R. Correia, E. Chehura, J. Li, S. W. James, and R. P. Tatam, "Enhanced sensitivity fibre Bragg grating (FBG) load sensor," Meas. Sci. Technol., vol. 21, no. 9, p. 094006, 2010.

[28] G. Ma, N. Mao, Y. Li, J. Jiang, H. Zhou, and C. Li, "The reusable load cell with protection applied for online monitoring of overhead transmission lines based on fiber Bragg grating," Sensors, vol. 16, no. 6, p. 922, 2016.

Sagar Jinachandran received the B.E. degree from the Birla Institute of Technology, Ranchi, India, in 2013, the M.Sc.Eng. degree from the University of Leeds, U.K., in 2014. He is currently pursuing the Ph.D. degree with the School of Electronics, Computer and Telecommunication Engineering, University of Wollongong, Australia. He was a Graduate Engineer in Muscat, Oman. His areas of research focus on the acoustic emission measurement based on specialty fiber Bragg grating sensors for high-temperature applications.

Huijun $\mathbf{L i}$ received the B.Sc. degree in mechanical engineering and the master's degree in materials engineering from Tianjin University in 1984, and the Ph.D. degree in materials engineering from the University of Wollongong, Australia, in 1996. He is currently a Professor with the Faculty of Engineering and Information Sciences, University of Wollongong. He has authored or co-authored over 300 scientific papers. His current research interests include high-strength steels, additive manufacturing, and high-temperature materials.

Jiangtao Xi received the B.E. degree from the Beijing Institute of Technology, Beijing, China, in 1982, the M.E. degree from Tsinghua University, Beijing, in 1985, and the Ph.D. degree from the University of Wollongong, Wollongong, Australia, in 1996, all in electrical engineering. He was a PostDoctoral Fellow at the Communications Research Laboratory, McMaster University, Hamilton, ON, Canada, from 1995 to 1996, and a Member of Technical Staff at Bell Laboratories, Lucent Technologies, Inc., Murray Hill, NJ, USA, from 1996 to 1998. He was the Chief Technical Officer with TCL IT Group Co., China, from 2000 to 2002. In 2003, he rejoined the University of Wollongong as a Senior Lecturer, where he is currently a Full Professor and the Head of the School of Electrical, Computer and Telecommunications Engineering. His research interests focus on signal processing and its applications in various areas, such as instrumentation and measurement, and communications.

B. Gangadhara Prusty is currently a Professor of Mechanical and Manufacturing Engineering with the University of New South Wales (UNSW), Australia, and also the Director of the ARC funded Centre for Automated Manufacture of Advanced Composites. He also leads the Advanced Structures and Materials Research Group, MECHENG School, UNSW. He is also the Deputy Director of the Centre for Sustainable Materials Research Technology. His research strengths are on the nano, micro, and macro-mechanics of fiber reinforced composites, and embodied with experimental and finite element modeling techniques. He led a number of major internationally collaborative projects, such as Systems for Crashworthiness and Robust Optimization for Imperfection Sensitive Composite Launcher Structures at UNSW through external funding. His current research interests focus on the online monitoring and processing of advanced composites using automated tape/fiber placement procedure. 
Yuliya Semenova received the bachelor's degree from Lviv Polytechnic National University, Lviv, Ukraine, in 1992, and the Ph.D. degree in physics of liquid crystals from the Ukrainian Academy of Sciences, Kiev, Ukraine, in 1999. From 1997 to 2001, she was a Research Fellow with the Faculty of Electro-Physics, Lviv Polytechnic National University. Since 2001, she has been with the School of Electronic and Communications Engineering, Dublin Institute of Technology, Dublin, Ireland. She is currently a Professor with the Photonics Research Centre, Dublin Institute of Technology. She has published more than 200 journals and conference papers. Her research interests include liquid crystal, photonics, and fiber-optic sensing.

Gerald Farrell received the Graduate (Hons.) degree in electronic engineering from University College Dublin, Dublin, Ireland, in 1979, and the Ph.D. degree from Trinity College Dublin, Dublin, for research in all-optical synchronization using self-pulsating laser diodes. From 1997 to 2003, he was the Director of the startup company PX Instrument Technology, where he focused on optical fiber system test and measurement systems. He spent a number of years as a Communications Systems Design Engineer developing optical fiber transmission systems before joining the Dublin Institute of Technology (DIT), Dublin. He is currently the Founder and the Director of the Photonics Research Centre, DIT. He has been the Head of the School of Electronic and Communications Engineering, DIT, since 2001. He has more than 300 publications in the area of photonics. His current research interests include several areas of optical sensing, including FBG interrogation systems, the modeling and applications of fiber bent loss to optical sensing, SMS and other fiber structure for sensing applications, PCF sensors for environmental sensing and for sensing strain in composite materials and medical devices, LC infiltrated PCF sensor, and microfiber and nanowire sensors for bio sensing.
Ginu Rajan received the Ph.D. degree in engineering from the Dublin Institute of Technology (DIT), Ireland, in 2009. He was the Project Manager with the Photonics Research Centre, DIT, from 2009 to 2012, and a VC Research Fellow with the University of New South Wales (UNSW) from 2012 to 2015. He is currently a Senior Fellow/Lecturer with the University of Wollongong and is also a Visiting Fellow with UNSW, Sydney. He has published over 135 articles in journals, conferences, and as book chapters, and two patents were also filed. His research and teaching interests include optical fiber sensing and its applications in a number of engineering areas. $\mathrm{He}$ is a member of conferences in the areas of optical fiber sensors and smart composite materials. He is the technical program committee chair in the areas of optical fiber sensors and smart composite materials. He is also a reviewer and an editorial board member of several journals and a reviewer for funding applications with the Portugal Science Foundation, Foundation for Polish Science and Australian Research Council. He is also an Editor of the books Optical Fiber Sensors: Advanced Techniques and Applications (CRC Press) and Structural Health Monitoring of Composite Structures Using Fiber Optic Methods (CRC Press). 